Preventive Care in Nursing and Midwifery Journal

2019; 9(2): 9-17

\title{
The Role of Organizational Justice in Nurses and Midwives' Satisfaction with Performance-Based Payment (Qasedak Project) in Zanjan Educational Hospitals
}

\author{
Jalili $\mathrm{R}^{1^{*}}$, Asefzadeh $\mathrm{S}^{2} \mathbb{0}$, Shoghli $\mathrm{A}^{3} \mathbb{E}$, Mohebbi $\mathrm{M}^{1}$ \\ ${ }^{* 1}$ MSc. Faculty of Health, Qazvin University of Medical Sciences, Qazvin, Iran \\ ${ }^{2}$ Associate Professor, School of Health, Qazvin University of Medical Sciences, Qazvin, Iran \\ ${ }^{3}$ Associate Professor, School of Medical, Zanjan University of Medical Sciences, Zanjan, Iran \\ *Corresponding Author: MSc. Faculty of Health, Qazvin University of Medical Sciences, Qazvin, Iran
}

Email: royaj148@gmail.com

Received: 25 Feb $2020 \quad$ Accepted: 9 May 2020

\begin{abstract}
Background: Performance-based payment makes rewards and outcomes result in paid satisfaction, which leads to the success and promotion of employee value and alignment with organizational goals in the light of organizational justice.

Objectives: This study aimed to assess The role of organizational Justice in Nurses and Midwives' Satisfaction with Performance-Based Payment (Qasedak Project) in Zanjan Educational Hospitals

Methods: This descriptive cross-sectional correlation study was conducted on 149 nurses and midwives in educational hospitals with Cochran formula. The researcher-made questionnaires of satisfaction based on P4P and organizational justice of Moorman and Niehoff were used, and data were analyzed using SPSS software and descriptive and analytic statistics (independent t-test, regression, analysis of variance, and nonparametric Spearman correlation coefficient and cross-tabulation).

Results: Nurses and midwives reported moderate organizational justice with an average of 55.7 and low merit pay satisfaction with an average of 13. There was a positive and significant correlation between organizational justice and job satisfaction $(r=0.65)$, the amount of merit pay and satisfaction $(r=0.33)$, and organizational justice and the amount of merit pay $(\mathrm{r}=0.23)$. The results revealed that organizational justice with a standard beta of 0.58 had a positive effect on the satisfaction with the merit pay received and alone accounted for $33 \%$ of the changes.

Conclusion: Since there was a positive and direct correlation between organizational justice and nursing and midwifery staff satisfaction, it is recommended that managers accomplish exact and accurate evaluation of staff performance by means of increasing staff's awareness of Qasedak project, providing timely feedback to them, and observing justice in the payment of rewards.
\end{abstract}

\section{Keywords: justice, midwife, nurse, performance-based payment, satisfaction}

\section{Introduction}

The human resources factor is the most important development factor in any country and organization. Therefore, considering human moods and motivations in any organization is highly necessary and privileged [1]. In healthcare organizations, attention to human resources is doubly significant as the health of the lively and efficient workforce of other organizations is guaranteed through the efforts of these organizations. Thus, fashioning satisfaction among workforce inside the organization prompts satisfaction in the whole organization and facilitates access to the ultimate goal of the organization which is advancement of health in societies. A significant section of human 
resources in these centers includes nurses and midwives [2] who, as a weighty and potent factor in the health care system, play an important role in the development of health care. Hence, the issue of their job satisfaction is vital and considerable [3].

Previous studies demonstrate that in order to accomplish maximum efficiency and effectiveness in the quality of services, nurses and midwives, in addition to having expertise and skills, must carry on to work with love and eagerness [4]. There are several definitions of job satisfaction in management texts. Victor Verome defines job satisfaction as a kind of mental perception of one's job. Job satisfaction refers to enjoying work, doing better work, having passion and delight in work, and getting the right reward for one's efforts. Job satisfaction, especially among nurses, is a major challenge for healthcare organizations [5]. Elsewhere, job dissatisfaction is interpreted as the discrepancy between what one expects to receive from one's job and what one actually receives [6]. The detrimental complication of job dissatisfaction is leaving the service. Helrigle et al. estimated the number of leave services among nurses to be between 60 or $70 \%$ [7].

Job satisfaction is predisposed by a number of factors, and the evaluation of employee's job satisfaction encompasses a complex set of multiple job elements and is not limited to a single factor [8]. One of the most important and effective aspects of job satisfaction is related to pays and benefits and their distribution. In so doing, modeling a fair payment system is one of the most central factors in attaining this goal [9]. Locke and Latham proposed that rewards and their consequences can result in paid satisfaction through performance-based pay and the provision of feedback. This, in turn, increases employee's success, enhances employee's value in the organization, and aligns personal goals with organizational goals, which overall culminate in employees' activities to be closer to the desired result and their positive evaluation of their job [10]. In this model, employees benefit from different levels of material rewards according to their level of performance, and the amount they receive is directly proportional to their level of performance. The Ministry of Health, Treatment and Medical Education, as the upholder of health, launched the substitution of performance-based payments in the form of the Health System Reform Plan since May 2014. This plan, as the new system of hospital management, aimed to establish an effective connection between pay and employee's performance and an organizational justice, increase job satisfaction, and consequently enhance quality and efficiency of services. The implementation of the Health System Reform Plan and the reduction of treatment tariffs in medical centers have led to an increase in referrals to such centers. Besides, the workload of employees, especially nurses who are in direct contact with patients, and midwifery staff have increased due to the promotion of natural childbirth. Although general health policies underscore the fact that the reform of the payment system is based on the quality of performance, increasing efficiency, creating fair income and motivating staff, sometimes unfair distribution of income and increase in income gap occur between different parts of the health system. The dissatisfaction of the nursing and midwifery group is very important as it adversely affects the quality of medical care. Therefore, their recruitment, retention, and job satisfaction depend on factors such as a trust, confidence, meritocracy, and evaluation and appreciation, all of which lie in organizational culture and constitute organizational justice [11]. In the literature of organization and management, the term organizational justice was first utilized by Greenberg (1987). According to Greenberg, organizational justice is related to employees' perceptions of justice and organization [12]. In organizational justice, it is defined as how to treat employees to feel that they have been treated fairly [13]. Human resources provide organizations with data in terms of time, effort, experience, skills, etc., and in return, the organization provides individuals with various outputs or benefits in economic, emotional, and social dimensions. How these benefits are distributed is extremely important [14]. Justice in management represents the perception of employees in terms of fair treatment at work, which in itself leads to the identification of three different components of justice in management, namely distributive 
justice, procedural justice, and interactive justice [15].

Distributive justice is rooted in theory of equality which was introduced by Adams (1965). In this theory, Jay Stacey Adams indicated that people tend to receive fair rewards for doing jobs. In other words, they benefit from rewards as much as their colleagues do. Equality, according to Adams, is accomplished when employees feel that the proportions of inputs (efforts) to their outputs (rewards) are equal to those of their colleagues. Employees who feel unequal show negative reactions, such as refusing to work, underemployment, and poor organizational citizenship behavior, and in its acute form, resigning from work [16]. Procedural justice at the organizational level implies the perceived fairness of the processes and procedures used in the decisions in allocating resources and rewards. According to procedural justice theory, when people observe current procedures as fair decisions about income distribution, they will be more driven to perform better, and if they think officials are unaware of their services and do not evaluate their performance accurately or evaluate their personal emotions, they will not be motivated. The term interactive justice was first used by Bays and Mug in 1986. Interactive justice expresses the distinction between the fairness of official procedures and the attitudes in personal relationships. Thus, the separation of interactive justice from procedural justice requires the distinction between procedures and how they are implemented [17].

Several studies have been conducted regarding nurses' job satisfaction and merit pay as well as the relationship between job satisfaction and organizational justice, and different results have been reported. Raisee et al. (2009), for example, reported the effect of merit pay on job satisfaction, which was not effective in increasing high satisfaction in nurses [18]. However, Bastani et al. (2015) investigated the satisfaction of nurses with the performance-based payment system and reported moderate to high satisfaction [19].

Due to numerous complaints against the nature and manner of implementation of the plan and performance-based payments in the nursing and midwifery staff of hospitals, the contradictions in the results of previous studies, and scantiness of studies on the relationship between organizational justice and this payment system, this research intended to determine the relationship between payment satisfaction and organizational justice in Zanjan educational hospitals.

\section{Methods}

The present study adhered to a descriptiveanalytical cross-sectional design and was carried out in 2017. The research community included nurses and midwives working in Zanjan educational hospitals. The Cochran's formula was applied to determine the sample size, and 149 people were recruited as the participants of the study.

In this study, the entry criteria included type of employment (official or contractual) and having consent to participate in the study. Exit criteria included incomplete questionnaire information and dissatisfaction during the completion of the questionnaire.

Three questionnaires were employed to collect data:

A) Demographic information review form that comprises of gender, age, marital status, work experience, employment status, academic degree, and job as midwife and nurse.

B) Moorman and Niehoff's organizational justice questionnaire has 20 questions in the form of a 5scale Likert. Scoring was considered as follows: I completely disagree $=1$, I disagree $=2$, I have no opinion $=3$, I agree $=4$, and I completely agree $=$ 5 . The minimum score for this questionnaire is 20 , and the maximum is 100 . In Iran, many studies have used this questionnaire to measure organizational justice. In the present study, the opinions of five experts in this field were used to measure validity. To determine the reliability of this questionnaire, Cronbach's alpha method (0.96) was confirmed by conducting a pilot study on 30 members of the research community and calculating the internal correlation of the questions.

C) The satisfaction of merit pay questionnaire has 7 questions and examines the dimensions of merit pay satisfaction including the quantitative merit pay (Question 1) as well as its quality such as merit pay instructions (questions 2,3,4,5), accuracy of performance information (question 6), and people's participation in decision-making of merit pay (question 7). The scores are based on the Likert scale (very low $=1$, low $=2$, somewhat 
$=3$, high $=4$, and very high $=5$ ). The minimum total score of the questionnaire is 7 , and the maximum is 35 . In the present study, in terms of reliability, Cronbach's alpha was found to be 0.91 . After receiving approval from the Research Committee, Graduate Studies and Ethics Committee of Qazvin University of Medical Sciences and obtaining a letter of introduction, the researcher showed the questionnaires to the respondents of Zanjan Educational and Medical Centers and then collected the data.

The data were analyzed using SPSS software version 17. In order to extract descriptive information, mean, standard deviation, and frequencies were considered. In addition, to analyze the data, independent t-test, analysis of variance, and non-parametric correlation coefficient of Spearman and cross-sectional tables were used. The significance level of statistical tests was determined to be 0.05 . Finally, regression model was carried out to appraise the level of satisfaction with the merit pay received.

\section{Results}

In this study, 149 persons were designated as the sample. According to the findings, a majority of the participants in the study $(80.2 \%)$ were females and married (79.3\%). Most of the participants were nurse $(72 \%)$ and had official employment (37\%), a bachelor's degree (93.9\%), a monthly merit pay of between 500,000 and 1 million tomans (44\%), and less than 10 years of work experience $(53 \%)$ (Table 1$)$.

Table 1: Demographic information of nursing and midwifery staff

\begin{tabular}{|c|c|c|c|}
\hline \multicolumn{2}{|c|}{ Variable } & \multirow{2}{*}{$\begin{array}{c}\text { Number (frequency) } \\
30\end{array}$} & \multirow{2}{*}{$\begin{array}{c}\text { Percentage } \\
19 / 8 \\
\end{array}$} \\
\hline \multirow{2}{*}{$\operatorname{Sex}$} & Male & & \\
\hline & Female & 119 & $80 / 2$ \\
\hline \multirow[t]{2}{*}{ Marital status } & Single & 31 & $20 / 7$ \\
\hline & Married & 118 & $79 / 3$ \\
\hline \multirow{3}{*}{ Level of education } & Associate & 4 & $2 / 4$ \\
\hline & Bachelor & 139 & $93 / 9$ \\
\hline & Master and higher & 6 & $3 / 7$ \\
\hline \multirow{3}{*}{ Type of employment } & Official & 55 & 37 \\
\hline & Contractual & 37 & $24 / 7$ \\
\hline & Contract & 57 & $38 / 3$ \\
\hline \multirow{3}{*}{ Job position } & Matron & 9 & $6 / 1$ \\
\hline & Nurse & 108 & $72 / 5$ \\
\hline & Midwife & 32 & $21 / 4$ \\
\hline Work experience & Years & $>10$ & 53 \\
\hline Merit pay received & Tomans & $500000-1000000$ & 44 \\
\hline
\end{tabular}

Based on the findings of the study, the mean scores of organizational justice satisfaction with merit pay were 55.7 and 13, respectively (Table 2)

Table 2: Mean score of total organizational justice and satisfaction of nursing and midwifery staff with merit pay

\begin{tabular}{ccc}
\hline Variable & Mean & Standard Deviation \\
\hline Organizational Justice & $55 / 7$ & $16 / 8$ \\
\hline Satisfaction Merit Pay & 13 & $5 / 1$ \\
\hline
\end{tabular}


To examine the relationship between demographic variables and the satisfaction of nurses and midwifery staff with performance-based payments and organizational justice, all variables were entered to the regression model. The results of the linear regression test, according to the step-by-step method, indicated that there was only a significant relationship between job position with organizational justice and merit pay satisfaction. Hence, midwifery staff with the highest score (68.75) and nurses with the lowest score (51.24). expressed the level of organizational justice in these hospitals, and the level of satisfaction in midwifery staff

was slightly higher than (15.67) the one in nurses (12) in terms of merit pay (Table 3). The results of the analysis of variance test also revealed that there was a significant relationship between the level of education and the type of employment with the amount of merit pay. In other words, employees with a master's degree and an average amount of 1 million and 700 thousand tomans have benefited from a higher amount of merit pay compared to other employees, and contractual employees with an average merit pay of 1 million and 450 thousand tomans received more merit pay than official and contract employees did.

Table 3: Post hoc test results of the relationship between organizational justice variables and satisfaction with merit pay and job position

\begin{tabular}{|c|c|c|c|c|}
\hline \multirow{7}{*}{$\begin{array}{c}\text { Organizational } \\
\text { Justice }\end{array}$} & & & Standard error & Level of significance \\
\hline & \multirow{2}{*}{ Midwife } & Nurse & $3 / 05213$ & $0 / 000$ \\
\hline & & Matron & $5 / 98139$ & $0 / 629$ \\
\hline & \multirow{2}{*}{ Nurse } & Midwife & $3 / 05213$ & $0 / 000$ \\
\hline & & Matron & $5 / 54813$ & $0 / 081$ \\
\hline & \multirow{2}{*}{ Matron } & Midwife & $5 / 98139$ & $0 / 629$ \\
\hline & & Nurse & $5 / 54813$ & $0 / 081$ \\
\hline \multirow{6}{*}{$\begin{array}{c}\text { Satisfaction } \\
\text { with merit pay }\end{array}$} & \multirow{2}{*}{ Midwife } & Nurse & $0 / 93305$ & $0 / 000$ \\
\hline & & Matron & $1 / 74457$ & $0 / 873$ \\
\hline & \multirow{2}{*}{ Nurse } & Midwife & $0 / 93305$ & $0 / 000$ \\
\hline & & Matron & $1 / 60960$ & $0 / 198$ \\
\hline & \multirow{2}{*}{ Matron } & Midwife & $1 / 74457$ & $0 / 873$ \\
\hline & & Nurse & $1 / 60960$ & $0 / 198$ \\
\hline
\end{tabular}

The results of Spearman's correlation coefficient in the study showed that there was a positive and significant correlation between satisfaction with merit pay and the amount of merit pay received ( $\mathrm{r}$ $=0.33$ ). This means that increasing the amount of merit pay can always result in satisfaction. One of the most important reasons for this, which is significant as a control factor, is individuals' mental perception of organizational justice and justice-oriented distribution of merit pay among individuals. The results of the study also revealed a positive and significant relationship between organizational justice and the amount of merit pay received $r=0.23$. In other words, with the increase in the amount of merit pay, the employees' sense of organizational justice increased to some extent. However, the correlation coefficient of 0.65 between organizational justice and the level of satisfaction with the merit pay was notable. In other words, when employees feel higher levels of organizational justice, their satisfaction with the merit pay they receive would be higher. Therefore, there is a close relationship between organizational justice and merit pay satisfaction, and satisfaction with merit pay depends on employees' perceptions of organizational justice (Figure 1). 


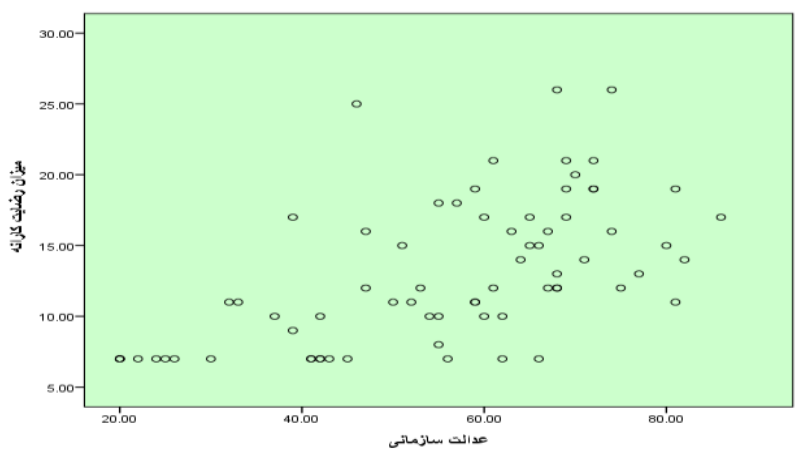

Figure 1: Distribution chart of the relationship between the variable of organizational justice and the level of satisfaction with merit pay received

According to the findings of the study, in multivariate analysis (multivariate regression), the main independent variable, namely organizational justice, which had the highest correlation with satisfaction with merit pay, entered the model step by step. The results revealed that organizational justice with a standard beta of 0.58 had a positive and significant effect on merit pay satisfaction. In other words, the only factor that can satisfy nurses and midwives with the merit pay is the mental perception of organizational justice. This value showed that a unit change in the perceived organizational justice changes to 0.58 in the merit pay satisfaction score. The explanatory coefficient of 0.33 indicates that the organizational justice variable alone accounted for $33 \%$ of the changes in satisfaction with merit pay. This means that any change in the perceived organizational justice of individuals resulted in a significant change in the level of merit pay satisfaction. A unit change in organizational justice affects nearly 33 percent of the satisfaction with merit pay. This means that another important factor in addition to the change in merit pay satisfaction is the perception of employees on the level of organizational justice. Therefore, it considerably depends on the justice perceived by the individuals in the organization. This study shows that the level of merit pay satisfaction can be influenced by the financial and material dimensions of satisfaction with organizational justice (Table 4)

\section{Table 4: Step-by-step multivariate analysis (multivariate regression) of satisfaction with merit pay received}

\begin{tabular}{|c|c|c|c|}
\hline \multicolumn{4}{|c|}{ Independent variable: Organizational justice } \\
\hline Standard coefficient & T Statistics & Level of sig & ficance \\
\hline 0.58 & 7.4 & $\mathbf{0 . 0}$ & \\
\hline \multicolumn{4}{|c|}{$\begin{array}{c}\text { Characteristics of regression model } \\
\text { Estimated }\end{array}$} \\
\hline $\begin{array}{l}\text { Multiple correlation } \\
\text { coefficient }\end{array}$ & $\begin{array}{c}\text { Explanatory } \\
\text { coefficient }\end{array}$ & $\begin{array}{l}\text { Modified } \\
\text { explanatory } \\
\text { coefficient }\end{array}$ & $\begin{array}{c}\text { standard } \\
\text { error }\end{array}$ \\
\hline 0.679 & 0.46 & 0.33 & 3.5 \\
\hline
\end{tabular}




\section{Discussion}

One of the most important and effective dimensions of any career is the satisfaction with salaries and benefits and their distribution, which are highly effective in the quantity and quality of services in the health system [9]. The aim of the present study was to examine the role of organizational justice in nursing and midwifery staff satisfaction with merit pay using the framework of the Health System Reform Plan in Zanjan educational hospitals. The results of the study indicated that nurses and midwives, despite their moderate perceptions of organizational justice, had low merit pay satisfaction.

As expected, the majority of respondents were women with bachelor's degrees. According to the results, the mean of organizational justice in nurses was 51.24, which showed that organizational justice in these hospitals was moderate. The results of previous studies such as Khosrowzadeh et al. [5] and Hassani and Karimi [20] are in line with the findings of the present study. In addition, our finding showed that there was no significant relationship between the independent variables of age, marital status, education, type of employment, work experience with organizational justice, while there was a significant relationship between job position and organizational justice. The highest mean score of organizational justice was assigned to midwives and the lowest to nurses.

The mean score for merit pay satisfaction was 13, indicating low satisfaction in these hospitals. Similar to the relationship between background variables and organizational justice variables, there was no significant relationship between these variables and the variable of merit pay satisfaction, except for the job position. Satisfaction in nursing staff was higher than the one in nurses. Domestic and global findings suggest that the average and low satisfaction of nurses, especially in the case of payment system dimension, and the difference in payments are almost consistent with our findings. The highest global satisfaction rate is for American nurses (41 percent) [21]. Most of the domestic studies such as Dehghani et al. [22], Khosrowzadeh et al. [5], and Bastani et al. confirmed this fact and indicated average or even less satisfaction by nurses. However, the results of the study by Gamal et al. (2008) are not consistent with the results of the present study. In their study, the practical workload of nurses before and after the implementation of the performance-based payment plan in the United Kingdom was examined, which indicates an increase in the satisfaction of nurses after the plan [23].

According to the results, there was a significant relationship between the level of education and the type of employment with the merit pay received. In other words, employees with a master's degree received more pay than other employees did, and contractual employees received more payment compared to official and contract employees.

Another result of this study was the direct relationship between the merit pay and the level of satisfaction with the merit pay and organizational justice. In other words, higher levels of merit pay can lead to more justice and merit pay satisfaction.

One of the important results of this study was the relatively high correlation between organizational justice and the level of satisfaction with the merit pay received. In other words, higher levels of organizational justice corresponded to participants' satisfaction with merit pay. Thus, satisfaction with the merit pay depended on individuals' understanding of organizational justice as it accounted for $33 \%$ of the changes in satisfaction with the merit pay received.

Since there was a positive and significant relationship between organizational justice and subscales of job satisfaction, including payment and salary system, the results of the study are consistent with the findings of Poursoltani Zarandi and Naderi [24] and Babazadeh et al. [25].

\section{Conclusion}

The findings of the present study presented a positive and significant relationship between organizational justice and satisfaction of nursing staff and midwifery from the merit pay received in the framework of the Health System Reform Plan. This means that the increase in organizational justice leads to satisfaction of the nursing and midwifery staff with regard to merit pay increases. One of the major limitations of this study was the mental states of the respondents while filling out the questionnaires, as at times they did not answer some questions. It is 
suggested that in order to create effective human resource management and thus increase satisfaction and the quality of medical services to patients, the performance of employees should be properly evaluated, and proper feedback should be provided to them in a timely manner. Besides, fairness should be observed in the payment of bonuses, and the personnel should be appreciated in a timely manner and publicly. And more importantly, managers should tend to have participatory management and use employees' opinions and ideas in decision-making processes. Staff and nursing managers should report problems and reasons for dissatisfaction of nurses and other staff with the implementation of the performance-based payment plan to the relevant departments of the university. This can help universities provide training sessions and transparency at each stage of payment to increase employee satisfaction.

Finally, sincere respect and behavior with staff and labor division on the basis of merit and competence can create a friendly and cordial atmosphere away from unhealthy competition in hospital environments

\section{Ethical considerations}

This research has been carried out with the code of ethics of IR.QUMS.REC.1396.221 from the ethics committee of Qazvin University of Medical Sciences.

\section{Acknowledgments}

This study is a part of a master's thesis entitled "The Role of Organizational Justice in Nurse and Midwife's Satisfaction with Performance-based Payment in the Health System Reform plan (Qasedak project) in Zanjan's Educational Hospitals." We highly appreciate the graduate students of Qazvin University of Medical Sciences, the hospital management, and the director of nursing and nursing staff of Zanjan University of Medical Sciences for their cooperation.

\section{Conflict of interest}

The authors declare that there is no conflict of interest.

\section{References}

1. Hoseyni M, Shahzaydi Sh. The effect of training continuous promotion of quality on job satisfaction of nurses in hospitals Tajrish and Taleghani of Tehran. Tehran: The first National Conference on Hospital Resource Management; 2003. [In Persian] 2. Haugo EB, Laschinger HS. Power and Opportunity in Public Health Nursing Work Environment. Public Health Nurs 1996; 12(1): 4249.

3. Mahmoudi H, Ebrahimian A, Soleimani M, Ebadi A, Hafezi S, Feizi F, Sadeghi M. The Study of Job Motivation Factors in Critical Care Nurses. J Behav Sci. 1386; 1(2): 171-78. [In Persian]

4. Pourghaz A, Nastie zaei N, Hezare Moghadam M. Job Satisfaction of Nurses in Zahedan Hospitals. Nurs Midwifery J. 2010; 8(3): 138-43 [in Persian]

5. Khosrozadeh M, Hosseini MA, Kashaninia Z, Sedghi Guye aghaj N, Amini M. Correlation between Organizational Justice and Job Satisfaction of Nurses in Educational Hospitals of Shiraz. Health Promot Manage J. 2016; 5(2): 1019. [In Persian]

6. Pfaf J. Factors Related to Job Satisfaction of Registered Nurses in Long- Term Care Facilities. Nurs Manage. 1987; 18(8): 51-5.

7. Mohsen pour L, Navi pour H, Ahmadi F. The Effect Of Participative Management Based On Quality Circles On Nurses' Job Satisfaction ; Herzberg Views. J Islamic Repub Iran Univ Med Sci. 1384; 3(4): 689-94. [In Persian]

8. Ravari A. Design And Standardization Of Clinical Nurses' Job Satisfaction Scale. PhD thesis in the field of nursing education, Tehran, Tarbiat Modarres University. 1388. [In Persian]

9. Abduljawad A, Al-Assaf A. Incentives for better performance in health care. Sultan Qaboos Univ Med J. 2011; 11(2): 201-206.

10. Heneman H, Judge TA. Compensation attitudes. In S. L. Rynes, \& B. Gerhart, (Eds). Compensation in organizations: current research and Practice. San Francisco, CA: Jossey-Bass; 2009: 61-103.

11. Tsai Y. Relationship between organizational culture, leadership behavior and job satisfaction. BMC Health Serv Res. 2011; 11(1): 98.

12. SeyyedJavadin SR, Farahi MM, Taheri Attar Gh. Understanding How Organizational Justice Aspects Affect different Aspects of Job \& 
Organizational Satisfaction. J Business Manage. 2008; 1(1): 55-70. [In Persian]

13. Naami A, Shokrkon H. Examine The Relationship Between Organizational Justice And Job Satisfaction Of Employees Of An Industrial Organization In Ahvaz. Educ Sci. 2005; 11(12):70. [In Persian]

14. Poursoltani zararndi TF, Naderi M. The Relationship Between Perceptions Of Organizational Justice With Job Satisfaction And Organizational Commitment Of Personnel In Islamic Republic Of Iran. Physical Education Organization. 2013; 3(5): 139-57. [In Persian]

15. Rezaeian, A. Expecting justice and justice in the organization. $8^{\text {th }}$ ed. Samt pub; 2009. [In Persian]

16. Safi MH, Mohamadi F, Arshi Sh (). The Relationship between Perceived Organizational Justice and Organizational Commitment with Job Satisfaction among Tehran Health Center Workers. J Research Center for Social Factors Affecting Health. 2015; 2(3): 172-81 [In Persian]

17. Sadeghi, M. Justice Coherence of organizations. Modiran magazine. 2009; 63- 70.

[In Persian]

18. Raeisi P, Alikhani M, Mobini Zadeh MR. Performance based payment in Shahid Hashemi Nejad Hospital. Health System J. 2000; 2(1,2): 27-36. [In Persian]

19. Bastani P, Ahmadzadeh MS, Abbasi Larki R, Khammania M. The Viewpoints Of Hospitals Personnel Regarding Performance Based Payment Plan In Shiraz University Of Medical Sciences In 2015. J Rafsanjan Univ Med Sci. 2017; 15(10): 943-54. [In Persian]
20. Hasani M, Karimi H. A Study On The Relationship Between Monitoring With Perceived Organizational Justice And Organizational Citizenship Behavior Among Medical Staff Of Urmia Imam Reza Hospital. J Urmia Nurs Mid Fac. 2014; 11(9): 814-22. [In Persian]

21. Ziapour A. An Investigation Of The Job Satisfaction And Related Factors In Nurses Of Kermanshah Hospitals. J Paramedical Sci Rehabilit. 2014; 2(2): 27-34. [In Persian]

22. Dehghani $M$, Hayavi Haghighi $\mathbf{M H}$, Mostafaie D, Estebsary F, Rafati S, Khorami F. The Relationship Between Social Capital And Organizational Citizenship Behavior Among Teaching Hospitals Staff At Hormozgan University Of Medical Sciences. J Mod Med Info Sci. 2014; 1(1): 25-34. [In Persian]

23. Gemmell I, Campbell S, Hann M, Sib bald B. Assessing Workload In General Practice In England Before And After The Introduction Of The Pay For Performance Contract. J Adv Nurs. 2009; 65(3): 509-15.

24. Poursoltani zararndi TF, Naderi M. The Relationship Between Perceptions of Organizational Justice with Job Satisfaction and Organizational Commitment of Personnel in Islamic Republic of Iran. Physic Educ Org. 2013; 3(5): 139-57. [In Persian]

25. Babazadeh T, Jamshidian A, Moradi M. An analysis of the relationship between organizational justice and job satisfaction among the staff of Isfahan's Welfare Organization. J Appl Sociol. 2014; 25(1): 71-84. [In Persian] 